\title{
Diving beneath the surface: addressing gender inequities among clinical investigators
}

\author{
Whitney H. Beeler, ${ }^{1}$ Lilia M. Cortina, ${ }^{2}$ and Reshma Jagsi ${ }^{1,3}$ \\ 'Department of Radiation Oncology, ${ }^{2}$ Departments of Psychology, Women's and Gender Studies, and Management \& Organizations, and ${ }^{3}$ Center for Bioethics and Social Sciences in Medicine, University of \\ Michigan, Ann Arbor, Michigan, USA.
}

E arlier this year, Dr. Anna Wåhlin made headlines for sending a $\$ 3.6$ million submarine beneath the ice shelf of Thwaites glacier to study - for the first time ever how warming Antarctic waters are contributing to glacial melting, rising sea levels, and climate change (1). Following this historic achievement came a series of articles and podcasts detailing not only the importance of her team's findings, but also the significance that she (a woman!) led this scientific mission. Indeed, Dr. Wåhlin is only the third woman in Sweden to obtain a $\mathrm{PhD}$ in oceanography; she named the submarine after a Norse goddess, Ran, to acknowledge the dearth of women in her field. Many find it disappointing that, in an era of remote Antarctic dives, directed evolution to engineer enzymes, and CRISPRmediated genome editing, the fact that women are leading these collaborative scientific efforts remains an accomplishment in and of itself.

The persistent underrepresentation of women among high-achieving scientists extends to the field of clinical investigation. In 2018, women constituted only $29 \%$ of US medical school faculty holding $\mathrm{MD}-\mathrm{PhD}$ or other dual doctoral degrees (2) and $27 \%$ of the members of the National Academy of Medicine (3). Recent public attention to egregious episodes of sexual harassment in other fields has heightened interest in understanding and mitigating the influence of sexual harassment on the careers of women in academic medicine. Indeed, in a comprehensive landmark report released last summer by the National Academies of Sciences, Engineering, and Medicine (NASEM), academic medicine was found to have the highest incidence of harassment of any field studied with female medical students $220 \%$ more likely to have experienced harassment than students in non-STEM disciplines (4).

A critical contribution of the NASEM report was its dissemination of a metaphor first developed by an author of this Viewpoint (LMC), suggesting that overt sexual coercion and unwanted sexual attention represent only "the tip of the iceberg" of sexual harassment in organizations. Beneath the surface lies the more pervasive problem of gender harassment, defined as both verbal and nonverbal behaviors that systematically objectify, humiliate, disparage, or convey hostility toward women and gender minorities. In medicine, the hierarchical model of academic training, in addition to the close and private physical interactions doctors have with their patients, enables these types of behaviors to occur routinely. Numerous studies have documented the negative effects of all three forms of sexual harassment namely, sexual coercion, unwanted sexual advances, and gender harassment - on the physical, psychological, and professional well-being of women (e.g., reduced productivity, decreased organizational commitment, increased rates of anxiety and depression, and greater turnover) (4). Because a multitude of environmental factors enable this type of misconduct to thrive, we suggest here (Figure 1) an extension of the iceberg metaphor. Beneath the surface, fostering the formation of the iceberg, are also a number of other challenges that must be addressed.

One key factor is unconscious bias, which has been documented in numerous rigorous social scientific studies and results in poorer evaluations for women than men, even in experimental designs that hold the level of accomplishments to be the same (5). These biases have an important effect on decisions for hiring and promotions and those that allocate compensation, leadership positions, publications, and funding, thereby constituting one mechanism by which women fail to reach positions of power and authority.

In addition, specific norms and policies in academic medicine persist that force the collision of professional and biological clocks for women and exacerbate rather than mitigate the challenges created by a society that continues to embrace a gendered division of domestic labor. These include lack of adequate leave policies both for childbearing mothers (which increases the risks of postnatal depression, burnout, and cessation of breastfeeding) and all new parents (which reinforces historical gender roles and deprives the newborn of time to bond with nonbirthing parents); expectations for attendance at scheduled meetings outside of typical working hours; a lack of clean, close, or suitable lactation rooms; and grant, promotions, or tenure clocks that limit flexibility for women who require time off to care for children or other familial dependents (5). Such norms and policies help to explain why $43 \%$ of women leave full-time STEM employment after the birth or adoption of their first child (6).

Some might argue that men and women are equally challenged by work-life obligations and that the increased attrition of female scientists is due to a fundamental difference in their aspirations or values compared with those of their male counterparts. However, even among a highly driven and similarly career-motivated cohort of NIH K08 and K23 award recipients, a team led by one of this Viewpoint's authors (RJ) has documented striking differences in the social context within which women function (7). Women are nearly twice as likely to have spouses or partners working full-time ( $86 \%$ vs. $45 \%$ ) and three times as likely to take time off when their usual childcare arrangements fall through

Conflict of interest: The authors have declared that no conflict of interest exists.

Copyright: ( 2019 , American Society for Clinical Investigation.

Reference information: J Clin Invest. 2019;129(9):3468-3471. https://doi.org/10.1172/JCI130901. 


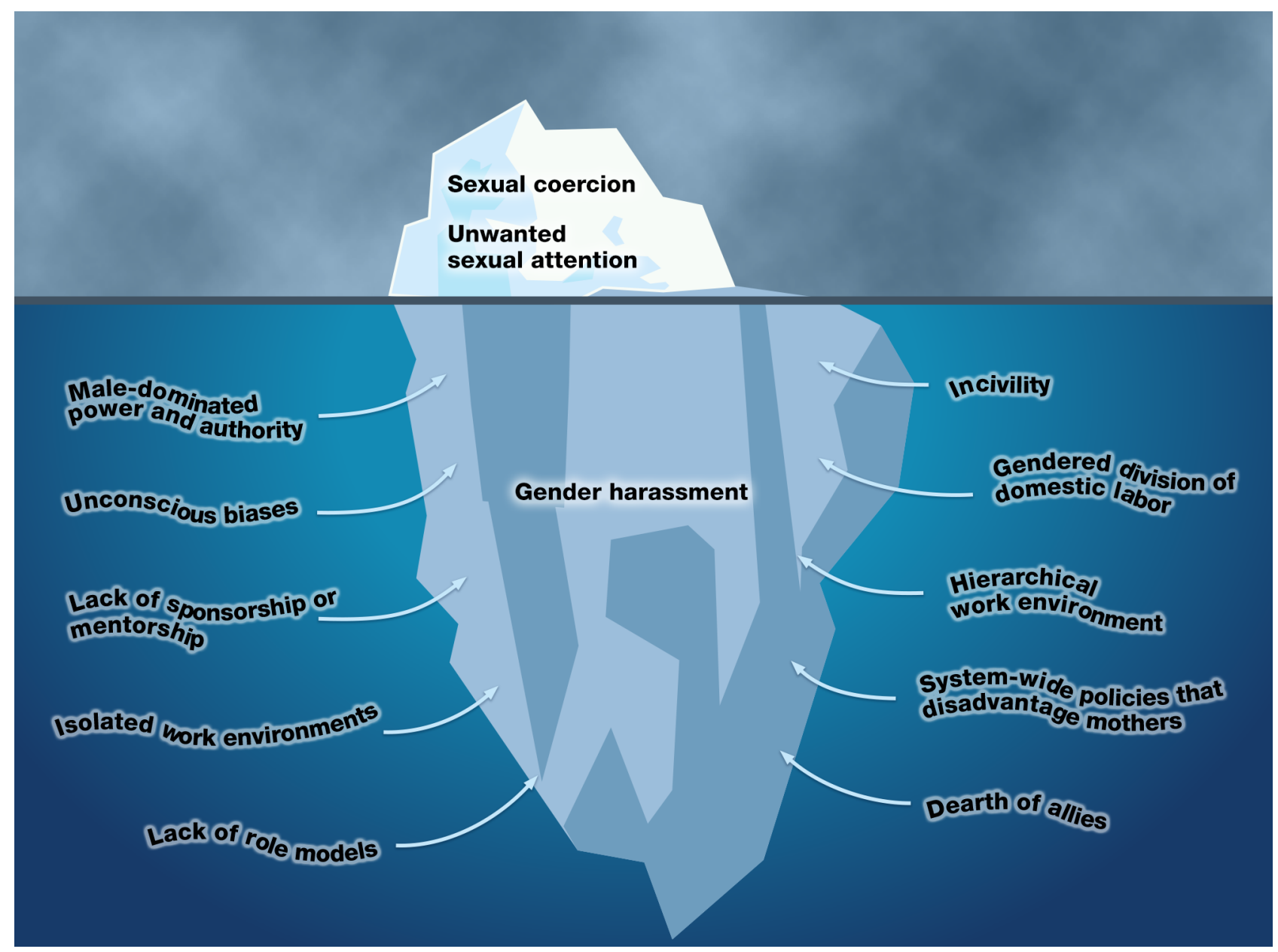

Figure 1. Overt sexual coercion and unwanted sexual attention represent only "the tip of the iceberg" of sexual harassment in organizations. In addition to pervasive problems of gender harassment, a myriad of environmental, organizational, and cultural factors in academic medicine exist beneath the surface of public visibility but contribute substantially to the harassment, attrition, and inequity experienced by women pursuing careers in clinical investigation. Illustrated by Mao Miyamoto.

(43\% vs. $12 \%)$; additionally, women spend - on average, even after adjusting for differences in spousal employment status and many other factors - 8.5 more hours per week on domestic duties than men (7). Over time, these differences can have substantial implications for female physician-scientists' careers, helping to explain why female $\mathrm{K}$ award recipients are less likely to receive R01 grants than similarly ambitious male $\mathrm{K}$ award recipients (8).

These and other systematic inequities ultimately create a shortage of women in scientific leadership positions, such as principal investigators (PIs) on $\mathrm{NIH}$ research project grants $(33 \%)$, department chairs within US medical schools (18\%), and editorial board members of major scientific journals (11.5\%) $(2,9,10)$. As a whole, women therefore have less influence over the experimental directions, budgetary decisions, and publication processes that are of paramount importance in academic medicine, not to mention the culture of academic medicine itself.

Having fewer women "at the top" of a given field or organization also provides fewer role models to whom junior female physician-scientists and students can look for inspiration. Although men can certainly serve as effective mentors, sponsors, and allies for women, academic medicine has not yet developed adequate structures to facilitate this support, and the male domination and isolation that persist in many areas of clinical investigation are key environmental risk factors for harassment in the first place $(4,5)$. To complicate matters, some men in the \#MeToo era now express reluctance to mentor women, or even meet privately with them, out of fear of false allegations. This fear, how- ever, is fueled by myths that women frequently fabricate or exaggerate claims of sexual harassment (11). In reality, women rarely report the harassing conduct they encounter, and statistically speaking, men are more likely to be sexually harassed by another man than accused of sexual harassment by a woman $(4,12)$. Until a major cultural shift transpires, this type of feedback loop will continue to perpetuate gender inequities in academic medicine.

Beyond the importance of equity for its own sake, the consequences of inequity in academic medicine are so profound that action is clearly needed. When half of matriculating medical students today are female, limiting the opportunities for women to succeed as clinical investigators directly limits access to the full pool of talent in a way that inhibits the capacity for discovery in the field. The next gener- 
ation of young physician-scientists needs an adequately diverse set of role models in order for them to envision and pursue success. Moreover, both the performance and collective intelligence of a group are objectively improved by the inclusion of diverse individuals and, specifically, women evidence that bears clear implications for the quality of clinical investigation (13).

Motivated organizations can look to a number of evidence-based interventions in order to mitigate gender inequity in academic medicine. Overt acts of sexual coercion and unwanted sexual attention should be swiftly and transparently penalized, with mechanisms already in place to enable easy reporting, provide legal assistance, and immediately remove the perpetrator from the work environment. Organizations must protect targets from retaliation and make it abundantly clear that no scientist - regardless of their renown, grant funding, or position - is immune. Indeed, a large meta-analysis evaluating the antecedents and consequences of workplace harassment suggests that the perception of organizational tolerance is in fact the strongest predictor for this type of behavior (14). Recent efforts by the National Science Foundation (NSF) to address sexual harassment may serve as an instructive example: Article $\mathrm{X}$ now requires awardees' institutions to notify the NSF when any PI or co-PI is under investigation or facing action related to sexual harassment or assault. A determination of guilt could result in swift suspension or removal of the PI from the grant, in addition to reduced funding or termination of the award altogether (15). The National Academy of Medicine (NAM) and National Academy of Science (NAS) have also acted by recently amending their bylaws to allow expulsion of known sexual harassers from their prestigious membership (3). Of course, such policies by the NSF, NAM, and NAS are aimed at removing perpetrators of the only most sexually aggressive and assaultive acts; consequences and remediation are also warranted for those committing gender harassment.

Recognizing that sexual harassment is often a symptom of deeper issues of culture and climate, organizations must ensure adequate attention to the promotion of civility and respect, while also fostering the inclusion of women throughout the field, including in positions of power and authority. Institutions should consider additional policies to attract and support female physician-scientists, such as more generous and flexible leave for childbearing mothers plus additional leave for all new parents, including adoptive, same-sex, and nonbirthing parents; clean, on-site lactation rooms; contractually guaranteed, subsidized, or on-site childcare; options for flextime and/or telecommuting; and resources to bring children to conferences, national meetings, or invited seminars if appropriate (5). Several institutions have implemented programs that provide financial resources to physician-scientist mothers, with these women subsequently securing enough grant funding to far exceed the initial investment (16). Other creative interventions that integrate career coaching and time banking have also demonstrated impressive outcomes in pilot initiatives (17).

Mentorship, sponsorship, and networking programs, such as the Executive Leadership in Academic Medicine program, have documented efficacy in preparing women for leadership roles, advancing women into higher academic positions, and assuaging feelings of isolation (18) Implicit-bias training has been shown to facilitate intentional behavior changes that promote gender equity among academic faculty members and should be strongly considered for all recruitment or promotions committee members, grant funders, peer reviewers, and scientific organizational leaders to ensure that female scientists receive an equitable and unbiased appraisal of their qualifications (19). Finally, the enactment of term limits (such as those recently imposed by the $\mathrm{NIH}$ ) and the expansion of search pools to include more women will ensure that all those with equivalent potential have ample opportunities to lead (20).

In her deep Antarctic dive, Dr. Wåhlin made major contributions, not only by directly contributing to the understanding of the important research questions she pursues, but also by promoting recognition of the great impact that an academy more inclusive of women could yield. The field of clinical investigation is fortunate to have at its disposal considerable evidence collected in many prior deep dives conducted by social scientists who have sought to understand the factors that lead to sexual harassment and gender inequity. Certainly, there is still a long way to go to reach gender parity in academic medicine - and an even longer path to achieve equity for those whose identities as women intersect with their place in other underrepresented groups, including the LGBTQ community and racial, ethnic, and religious minority populations. Although the NASEM report and recent stories in the era of \#MeToo may seem to paint a relatively dismal picture of our progress thus far, growing attention from institutions and grant agencies provide hope that changes may also be brewing beneath the surface. Given the ingenuity of scientists and their seemingly endless lists of accomplishments to date, we are certain that gender equity is an achievable goal and one worthy of steadfast pursuit.

Address correspondence to: Reshma Jagsi, 1500 East Medical Center Drive, Ann Arbor, Michigan 48109, USA. Phone:734.736.4300; Email:rjagsi@med.umich.edu.

1. Beeler C. Antarctica Dispatch 1-9. PRI's The World. Public Radio International. February 26-March 22, 2019.

2. Association of American Medical Colleges. AAMC Data. U.S. Medical School Faculty, 2018. Table 10: U.S. Medical School Faculty by Sex and Degree. http://www.aamc.org/download/495042/ data/18table10.pdf. Published April 30, 2019. Accessed May 29, 2019.

3. Waldman M. National Academy of Sciences to allow expulsion of harassers. Science. June 3, 2019. http://www.sciencemag.org/news/2019/06/ national-academy-sciences-allow-expulsionharassers. Accessed June 10, 2019.

4. National Academies of Sciences, Engineering, Medicine. Sexual Harassment of Women: Climate, Culture, and Consequences in Academic Sciences, Engineering, and Medicine. Washington, DC, USA: The National Academies Press; 2018.

5. Mangurian C, Linos E, Sarkar U, Rodriguez C, Jagsi R. What's holding women in medicine back from leadership. Harvard Business Review. June 19, 2018. http://hbr.org/2018/06/whats-holding-women-in-medicine-back-from-leadership. Accessed June 26, 2019.

6. Cech EA, Blair-Loy M. The changing career trajectories of new parents in STEM. Proc Natl Acad Sci U S A. 2019;116(10):4182-4187.

7. Jolly S, Griffith KA, DeCastro R, Stewart A, Ubel $P$, Jagsi R. Gender differences in time spent on parenting and domestic responsibilities by high-achieving young physician-researchers. Ann Intern Med. 2014;160(5):344-353.

8. Jagsi R, Motomura AR, Griffith KA, Rangarajan S, Ubel PA. Sex differences in attainment of independent funding by career 
development awardees. Ann Intern Med. 2009;151(11):804-811.

9. NIH Statistical Analysis and Reporting. Research Grant Investigators: Percentage of Women, by Mechanism. NIH Data Book Report ID: 169. http://report.nih.gov/nihdatabook/report/169. Updated December 2018. Accessed May 29, 2019.

10. Jagsi R, Tarbell NJ, Henault LE, Chang Y, Hylek EM. The representation of women on the editorial boards of major medical journals: a 35-year perspective. Arch Intern Med. 2008;168(5):544-548.

11. Lonsway KA, Cortina LM, Magley VJ. Sexual harassment mythology: Definition, conceptualization, and measurement. Sex Roles: A Journal of Research. 2008;58(9-10):599-615.

12. Fielding J. Men fear false allegations. Women fear sexual misconduct, assault, and rape. Minnesota Law Review. 2018;103(5). http://www. minnesotalawreview.org/2018/11/men-fear- false-allegations-women-fear-sexual-misconduct-assault-and-rape. Published November 25, 2018. Accessed November 25, 2018.

13. Woolley AW, Chabris CF, Pentland A, Hashmi $\mathrm{N}$, Malone TW. Evidence for a collective intelligence factor in the performance of human groups. Science. 2010;330(6004):686-688.

14. Willness CR, Steel P, Lee K. A meta-analysis of the antecedents and consequences of workplace sexual harassment. Personnel Psychology. 2007;60(1):127-162.

15. NSF announces new measures to protect research community from harassment [news release]. Alexandria, Virginia, USA: National Science Foundation Public Affairs; September 19, 2018. https://www.nsf.gov/news/news_summ.jsp?cntn id=296610. Accessed May 31, 2019.

16. Jagsi R, Butterton JR, Starr R, Tarbell NJ. A targeted intervention for the career development of women in academic medicine. Arch Intern Med.
2007;167(4):343-345.

17. Fassiotto M, Simard C, Sandborg C, Valantine H, Raymond J. An Integrated Career Coaching and Time-Banking System Promoting Flexibility, Wellness, and Success: A Pilot Program at Stanford University School of Medicine. Acad Med. 2018;93(6):881-887.

18. Richman RC, and Magrane D. Spotlight: The Executive Leadership in Academic Medicine (ELAM) Program for Women - Fourteen Years of Academic Women Leaders in Medicine, Dentistry, and Public Health. Faculty Vitae. http://www. aamc.org/members/gfa/faculty_vitae/148588/ elam.html. Accessed June 10, 2019.

19. Carnes M, et al. The effect of an intervention to break the gender bias habit for faculty at one institution: a cluster randomized, controlled trial. Acad Med. 2015;90(2):221-230.

20. Kaiser J. NIH limits reign of chiefs. Science. 2019;364(6439):423. 